\title{
A Retrospective Analysis of COVID-19 ARDS Patients Successfully Extubated to High Flow Nasal Cannula Oxygen Therapy
}

\section{GULCIN HILAL ALAY ( $\square$ gulcinhilalalay@gmail.com )}

Istanbul University Istanbul Faculty of Medicine: Istanbul Universitesi Istanbul Tip Fakultesi https://orcid.org/0000-0001-9259-9249

\section{Perihan Ergin Ozcan}

Istanbul University Istanbul Faculty of Medicine: Istanbul Universitesi Istanbul Tip Fakultesi

\section{Ozlem Polat}

Istanbul University Istanbul Faculty of Medicine: Istanbul Universitesi Istanbul Tip Fakultesi

\section{Ilkay Anakli}

Istanbul University Istanbul Faculty of Medicine: Istanbul Universitesi Istanbul Tip Fakultesi

\section{Gunseli Orhun}

Istanbul University Istanbul Faculty of Medicine: Istanbul Universitesi Istanbul Tip Fakultesi

\section{Verda Tuna}

Istanbul University Istanbul Faculty of Medicine: Istanbul Universitesi Istanbul Tip Fakultesi

\section{Emre Celiksoy}

Istanbul University Istanbul Faculty of Medicine: Istanbul Universitesi Istanbul Tip Fakultesi

\section{Mehmet Kilic}

Istanbul University Istanbul Faculty of Medicine: Istanbul Universitesi Istanbul Tip Fakultesi

\section{Mutlu Mercan}

Istanbul University Istanbul Faculty of Medicine: Istanbul Universitesi Istanbul Tip Fakultesi

\section{Figen Esen}

Istanbul University Istanbul Faculty of Medicine: Istanbul Universitesi Istanbul Tip Fakultesi

\section{Research}

Keywords: Acute Respiratory Distress Syndrome, COVID-19, extubation, high flow nasal cannula oxygen therapy,weaning

Posted Date: May 7th, 2021

DOI: https://doi.org/10.21203/rs.3.rs-482283/v1 
License: (c) (i) This work is licensed under a Creative Commons Attribution 4.0 International License. Read Full License 


\section{Abstract \\ Background}

Coronavirus disease- 2019 (COVID-19) related to acute respiratory distress syndrome (ARDS) caused by the highly infectious SARS-CoV-2 novel coronavirus is a major cause of death during the pandemic period. Here we aim to present the retrospective data analysis of extubation success to High Flow Nasal Cannula Oxygen Therapy (HFNO) in COVID-19 ARDS patients.

\section{Methods}

The data of 22 laboratory-confirmed COVID-19 ARDS patients who were extubated to HFNO therapy at an intensive care unit (ICU) were analyzed. Respiratory variables as well as demographic characteristics were collected on admission. The mechanical ventilation volumes and pressures together with blood gas measurements were recorded during the intubation period. $\mathrm{HFNO}$ flow rate, $\mathrm{FiO}_{2}$, and oxygenation variables were collected 5 consecutive days after extubation. The reintubation rate within the 5 days following planned extubation, duration of ICU stay, and mortality were recorded.

\section{Results}

Among 22 patients, 16 were male $(72.7 \%)$ and the mean age was $69.9 \pm 13,2$ years with the highest comorbidity being hypertension (59.1\%). The duration between symptom initiation to ICU admission was $6.5 \pm 7,9$ days where nearly all patients were intubated on the same day. Twenty patients were successfully extubated to HFNO and 2 patients experienced reintubation. The mean duration of HFNO treatment was $4.8 \pm 3.6$ days and the length of ICU stay was $17.4 \pm 6$ days. The ICU mortality ratio of this complete data was $13.6 \%(3 / 22)$.

\section{Conclusion}

Among high-risk ARDS COVID-19 patients who have undergone extubation, HFNO therapy should be considered for preventing reintubation and post-extubation respiratory failure.

\section{Introduction}

High Flow Nasal Oxygen therapy (HFNO) is one of the newer methods of oxygenation commonly used in critical care during acute hypoxemic respiratory failure that can deliver heated and humidified gas up to $100 \%$ oxygen at a maximum flow of $60 \mathrm{~L} \mathrm{minute}^{-1}$ via nasal cannula. It has also been reported that HFNO can generate flow-dependent, low-level positive airway pressure, reduce airway resistance, and flush nasopharyngeal dead space [1]. 
In COVID-19 patients with acute respiratory failure, HFNO reduced the intubation rate compared to noninvasive ventilation (NIV) when used as initial support [2]. HFNO was shown to be superior to conventional oxygen treatment (COT) in reducing treatment failure when used as a primary support strategy and in reducing rates of extubation failure and reintubation when used after extubation [2]. However, there is an important concern that the high gas flow used might cause aerosol dispersion leading to the transmission of the virus into the environment. In vitro studies demonstrated that generation and dispersion of bio-aerosols via HFNO show a similar risk to standard oxygen masks [3].

Thinking about the advantages of HFNO in reducing the risk of intubation and the need for mechanical ventilation, it is not wise to discard this technique for the support of acute respiratory failure patients due to COVID-19. HFNO was widely used in our institution during the pandemic period both before and after invasive mechanical ventilation. In this retrospective data analysis, we aimed to report extubation success to HFNO and report the outcome data of COVID-19 ARDS patients.

\section{Material And Methods}

This retrospective study was conducted at Istanbul University Hospital after ethics approval was obtained from the hospital's local ethics committee (Approval number: 04/06/2020-89807). Twenty-two ARDS patients (18 years of age or older) with laboratory-confirmed COVID-19 infection who were admitted to the hospital's four ICUs between 18 March 2020 and 30 May 2020 were included in this analysis. The written informed consent from individual patients was waived due to the nature of the retrospective chart review. The directive for follow-up of COVID-19 patients was documented on Supplement 1. COVID-19 disease was defined as a positive result on a reverse-transcriptase-polymerase-chain-reaction (RT-PCR) assay of a nasopharyngeal swab collected by the local hospital health authority. SARS-CoV-2 pneumonia was diagnosed according to World Health Organization guidance and those patients who required respiratory support or had oxygen saturation below $90 \%$ with a standard oxygen mask were admitted to the ICU. ARDS was defined according to Berlin definition [4]. Data was collected from available electronic medical records and patient files by the attendings responsible for the research facilities of the Department of Critical Care Medicine of the Istanbul Medical Faculty.

The demographic and clinical data including age, sex, admission disease severity scores [Acute Physiology and Chronic Health Evaluation II (APACHE II) and Sequential Organ Failure Assessment (SOFA) score], underlying comorbidities (chronic cardiac disease, hypertension, chronic pulmonary disease, diabetes mellitus, chronic renal failure, chronic liver disease, malignancies, cerebrovascular disease, autoimmune disease, and immunosuppressive state), duration between symptom initiation and ICU admission, and intubation period were recorded.

$\mathrm{PaO}_{2} / \mathrm{FiO}_{2}$ (arterial oxygen partial pressure/fractional inspired oxygen) ratio before intubation, days in mechanical ventilation were recorded. Blood gas analysis and respiratory parameters including inspiratory support pressure, positive end-expiratory pressure (PEEP), respiratory frequency, tidal volume $(\mathrm{Vt})$, and frequency, as well as $\mathrm{PaO}_{2} / \mathrm{FiO}_{2}$ ratio right before extubation, were added to the data chart. 
Mechanical ventilation volumes, pressures, and blood gas analysis results were recorded during the intubation period.

The weaning protocol included daily screening for weaning readiness according to the respiratory and clinical criteria. Patients were extubated when they fulfill the criteria of extubation (low PEEP level (5-8 $\mathrm{cm} \mathrm{H}_{2} \mathrm{O}$ ), with no electrolyte disturbance, provided hemodynamic stability, interrupted sedation and followed up in spontaneous breathing in pressure support mode, good state of consciousness, received sufficient Vt (at least $5 \mathrm{ml} \mathrm{kg}^{-1}$ ), and had sufficient cough reflex were evaluated in terms of sputum amount, character and viscosity, aspiration frequency of more than 2 hours, pain control were achieved, breath rate is $<30 / \mathrm{min}$, oxygen saturation $\left(\mathrm{SpO}_{2}\right)>90 \%, \mathrm{PaO}_{2}>60 \mathrm{mmHg}$, rapid shallow breathing index $<105$ ). Patients were continuously treated by $\mathrm{HFNO}$ alone with a flow and $\mathrm{FiO}_{2}$ adjusted to obtain adequate oxygenation, with a $\mathrm{SpO}_{2}$ as measured by pulse oximeter of at least $92 \%$. To provide sufficient humidification, the temperature of the heated humidifier was set at $37^{\circ} \mathrm{C}$. When there were no signs of respiratory failure (respiratory rate $>35$ minute $^{-1}$ more than five minutes, hypoxemia that $\mathrm{SpO}_{2}<90 \%$, tachycardia that heart rate $(\mathrm{HR})>140$ minute $^{-1}$ or $20 \%$ increase, bradycardia that $20 \%$ reduction in $\mathrm{HR}$, hypertension that systolic blood pressure $>180 \mathrm{mmHg}$, hypotension that systolic blood pressure < $90 \mathrm{mmHg}$, acidosis that $\mathrm{pH}<7.32$ and $>10 \mathrm{mmHg}$ increase in $\mathrm{PaCO}_{2}$ (arterial carbon dioxide partial pressure), consciousness changes that agitation, sweating or anxiety symptoms, cyanosis, findings of increased breathing effort that accessory muscle use, stress symptoms on the face, increased breathlessness) after extubation, treatment was stopped and switched to standard oxygen.

$\mathrm{HFNO}$ flow rate, $\mathrm{FiO}_{2}$, and oxygenation variables including $\mathrm{PaO}_{2}, \mathrm{PaCO}_{2}, \mathrm{SaO}_{2}$ (arterial oxygen saturation) were collected 5 consecutive days after extubation. The reintubation rate within the 48 hours and 5 days following extubation, ICU length of stay, and mortality were recorded. Data collection was stopped in those patients who were either switch to COT or invasive mechanical ventilation.

\section{Statistical analysis}

Data analysis was performed with SPSS (IBM SPSS Statistics for Windows, Version 20.0. Armonk, NY: IBM Corp.) One sample Kolmogorov-Smirnov test was performed to evaluate the distribution of the continuous variables. The categorical variables were presented as number and percentage values. The mean, standard deviation, minimum and maximum values of continuous variables were presented. Spearman correlation analysis was performed to evaluate the association between clinical features and pre-extubation mechanic ventilation volumes, pressures, and blood gas parameters. A p-value less than .05 was considered statistically significant.

\section{Results}

The demographic and clinical characteristics of the patients are summarized in Table 1. The mean age was $69.9 \pm 13.2$ years, and $72.7 \%(16 / 22)$ of patients were male. The mean APACHE II and median SOFA 
scores of the patients on ICU admission were $19.5 \pm 6.8$ and $5.4 \pm 2.6$, respectively. 
Table 1

Demographic characteristics and clinical features of study population

\begin{tabular}{|c|c|c|}
\hline & $\begin{array}{l}\text { Mean } \pm S D \text { / } \\
\mathrm{n}\end{array}$ & $\begin{array}{l}\min -\max / \\
\%\end{array}$ \\
\hline Age (years) & $69.9 \pm 13.2$ & $46-89$ \\
\hline $\mathrm{BMI}\left(\mathrm{kg} \mathrm{m}^{-2}\right)$ & $27.8 \pm 3$ & $23-36$ \\
\hline Gender (n / \%) & 16 & $72.7 \%$ \\
\hline - Male & 6 & $27.3 \%$ \\
\hline \multicolumn{3}{|l|}{ - Female } \\
\hline Chronic disease (n / \%) & 8 & $36.4 \%$ \\
\hline - Cardiac disease & 13 & $59.1 \%$ \\
\hline - Hypertension & 11 & $50 \%$ \\
\hline - Diabetes mellitus & 5 & $22.7 \%$ \\
\hline - Pulmonary disease & 2 & $9.1 \%$ \\
\hline - Cerebrovascular disease & 1 & $4.5 \%$ \\
\hline - Malignancy & 1 & $4.5 \%$ \\
\hline - Renal disease & 1 & $4.5 \%$ \\
\hline \multicolumn{3}{|l|}{ - Liver disease } \\
\hline Symptom initiation to ICU admission (days) & $6.5 \pm 7.9$ & $1-36$ \\
\hline Symptom initiation to intubation (days) & $6.8 \pm 8.1$ & $1-37$ \\
\hline APACHE II score at ICU admission & $19.5 \pm 6.8$ & $8-34$ \\
\hline SOFA score at ICU admission & $5.4 \pm 2.6$ & $3-13$ \\
\hline Maximum SOFA score & $7,8 \pm 2.3$ & $4-15$ \\
\hline $\mathrm{PaO}_{2} / \mathrm{FiO}_{2}$ before intubation & $111.4 \pm 31.9$ & $65-185$ \\
\hline Duration of mechanical ventilation (days) & $9 \pm 5.3$ & $2-21$ \\
\hline ICU hospitalization (days) & $17.4 \pm 6$ & $6-28$ \\
\hline HFNO treatment (days) & $4.8 \pm 3.6$ & $1-15$ \\
\hline Successful weaning (n / \%) & 20 & $90 \%$ \\
\hline
\end{tabular}

BMI: body mass index, ICU: intensive care unit, APACHE II: acute physiology and chronic health evaluation II, SOFA: sequential organ failure assessment, HFNO: high flow nasal oxygen 


\begin{tabular}{|lll|}
\hline & Mean \pm SD / & min-max / \\
& $\mathbf{n}$ & $\%$ \\
\hline Reintubation in $48 \mathrm{~h}(\mathrm{n} / \%)$ & 1 & $4.5 \%$ \\
\hline Reintubation in 5 days (n / \%) & 1 & $4.5 \%$ \\
\hline Death ( $\mathrm{n} / \%)$ & 3 & $13.6 \%$ \\
\hline $\begin{array}{l}\text { BMI: body mass index, ICU: intensive care unit, APACHE II: acute physiology and chronic health } \\
\text { evaluation II, SOFA: sequential organ failure assessment, HFNO: high flow nasal oxygen }\end{array}$ \\
\hline
\end{tabular}

The leading comorbidities among our patients were chronic cardiac failure, hypertension, and diabetes and their frequencies were $36.4 \%(8 / 22), 59.1 \%(13 / 22)$, and $50 \%(11 / 22)$, respectively. The mean duration from symptom to ICU admission and intubation were $6.5 \pm 7.9$ and $6.8 \pm 8.1$ days, respectively. Sixteen patients were intubated on the same day of ICU admission. Patients were extubated to HFNO after a mean of $9 \pm 5.3$ days of mechanical ventilation. Twenty patients were extubated successfully to HFNO, one patient was reintubated in 48 hours and the other patients were reintubated within 5 days after extubation. Three out of 22 patients died (13.6\%).

Table 2 shows mean records of blood gasses and respiratory parameters right before extubation. The slight increase in $\mathrm{HCO}_{3}\left(30.3 \pm 5.1 \mathrm{mmol} \mathrm{L}^{-1}\right)$ and base excess $(\mathrm{BE})\left(6.3 \pm 5.3 \mathrm{mmol} \mathrm{L}^{-1}\right)$ levels were observed with a mean respiratory rate of $17.3 \pm 3.9$ minute $^{-1}$. Mean PEEP was $7.1 \pm 1.0 \mathrm{cmH}_{2} \mathrm{O}$ and improvement in the $\mathrm{PaO}_{2} / \mathrm{FiO}_{2}$ ratio $(247.6 \pm 73.1)$ was evident compared with the initial values. The mean HFNO treatment after extubation was $4.8 \pm 3.6$ days and the length of ICU stay was $17.4 \pm 6$ days. 
Table 2

Respiratory parameters and blood gas analysis values before extubation

\begin{tabular}{|c|c|}
\hline & Mean $\pm S D$ \\
\hline $\mathrm{pH}$ & $7.45 \pm 0.04$ \\
\hline $\mathrm{PO}_{2}(\mathrm{mmHg})$ & $93.2 \pm 23.7$ \\
\hline $\mathrm{PCO}_{2}(\mathrm{mmHg})$ & $43.2 \pm 7.1$ \\
\hline 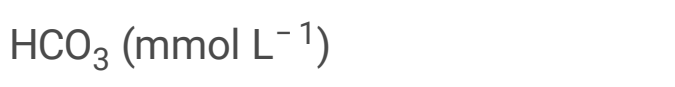 & $30.3 \pm 5.1$ \\
\hline Base excess & $6.3 \pm 5.3$ \\
\hline $\mathrm{SaO}_{2}(\%)$ & $96.7 \pm 1.7$ \\
\hline \multirow[t]{2}{*}{ Respiratory rate (breathe minute ${ }^{-1}$ ) } & $17.3 \pm 3.9$ \\
\hline & (median: 15.5) \\
\hline Tidal Volume (ml) & $583.1 \pm 150.8$ \\
\hline $\mathrm{RR} / \mathrm{Vt}$ & $31.1 \pm 11.2$ \\
\hline $\operatorname{PEEP}\left(\mathrm{cm} \mathrm{H}_{2} \mathrm{O}\right)$ & $7.1 \pm 1.0$ \\
\hline Inspiration support $\left(\mathrm{cm} \mathrm{H}_{2} \mathrm{O}\right)$ & $11.7 \pm 3.3$ \\
\hline $\mathrm{FiO}_{2}$ & $0.38 \pm 0.04$ \\
\hline $\mathrm{PaO}_{2} / \mathrm{FiO}_{2}$ & $247.6 \pm 73.1$ \\
\hline \multicolumn{2}{|c|}{$\begin{array}{l}\mathrm{PaO}_{2} \text { : arterial oxygen partial pressure, } \mathrm{FiO}_{2} \text { : fractional inspired oxygen, } \mathrm{RR} \text { : respiratory rate, Vt: tidal } \\
\text { volume, } \mathrm{SaO}_{2}: \text { arterial oxygen saturation, } \mathrm{PEEP} \text { : positive end expiratory pressure }\end{array}$} \\
\hline
\end{tabular}

Patients' gas exchange, $\mathrm{HFNO}$ flow, and $\mathrm{FiO}_{2}$ after 5 days of extubation were depicted in Table 3. Five days after extubation the mean $\mathrm{PaO}_{2} / \mathrm{FiO}_{2}$ ratio was $180.3 \pm 46.1$ with a mean $\mathrm{FiO}_{2}$ and flow rate of 0.46 \pm 0.07 and $42.2 \pm 8.7 \% \mathrm{~L}_{\text {minute }}{ }^{-1}$, respectively. Table 4 demonstrates the correlation between the duration of HFNO treatment after extubation with clinical features and pre-extubation ventilator parameters and blood gasses. There was a significant correlation with $\mathrm{pH}$ level before extubation and HFNO treatment duration $(r=0.438 ; p=0.041)$. Higher pressure support levels before extubation related to longer HFNO duration with no significance $(r=-0.409 ; p=0.059)$. 
Table 3

Five days follow-up of $\mathrm{HFNO}$, flow, $\mathrm{FiO}_{2}$ and blood gas values after extubation

\begin{tabular}{|c|c|c|c|c|c|}
\hline & $\begin{array}{l}\text { 1st day } \\
\text { Mean } \pm S D \\
\text { (min-max) } \\
(n=22)\end{array}$ & $\begin{array}{l}\text { 2nd day } \\
\text { Mean } \pm S D \\
(\min -\max ) \\
(n=20)\end{array}$ & $\begin{array}{l}\text { 3rd day } \\
\text { Mean } \pm S D \\
(\min -\max ) \\
(n=16)\end{array}$ & $\begin{array}{l}\text { 4th day } \\
\text { Mean } \pm S D \\
(\min -\max ) \\
(n=11)\end{array}$ & $\begin{array}{l}\text { 5th day } \\
\text { Mean } \pm S D \\
\text { (min-max) } \\
(n=9)\end{array}$ \\
\hline $\mathrm{pH}$ & $\begin{array}{l}7.44 \pm 0.7 \\
7.27-7.55\end{array}$ & $\begin{array}{l}7.44 \pm 0.5 \\
(7.29-7.55)\end{array}$ & $\begin{array}{l}7.44 \pm 0.7 \\
(7.21-7.53)\end{array}$ & $\begin{array}{l}7.46 \pm 0.05 \\
(7.32-7.55)\end{array}$ & $\begin{array}{l}7.42 \pm 0.08 \\
(7.30-7.54)\end{array}$ \\
\hline $\mathrm{PaO}_{2}(\mathrm{mmHg})$ & $\begin{array}{l}102.1 \pm 27.2 \\
58-146\end{array}$ & $\begin{array}{l}90.2 \pm 27.9 \\
(61-146)\end{array}$ & $\begin{array}{l}78.8 \pm 13.3 \\
(62-109)\end{array}$ & $\begin{array}{l}83.9 \pm 12.2 \\
(65-101)\end{array}$ & $\begin{array}{l}80.8 \pm 15.7 \\
(60-108)\end{array}$ \\
\hline $\mathrm{PaCO}_{2}(\mathrm{mmHg})$ & $\begin{array}{l}41.7 \pm 7.8 \\
32-64\end{array}$ & $\begin{array}{l}42.4 \pm 9.8 \\
25-66\end{array}$ & $\begin{array}{l}40.5 \pm 7.7 \\
(31-58)\end{array}$ & $\begin{array}{l}40 \pm 5.5 \\
(34-53)\end{array}$ & $\begin{array}{l}38.4 \pm 4.2 \\
(33-45)\end{array}$ \\
\hline $\mathrm{SaO}_{2}(\%)$ & $\begin{array}{l}96.6 \pm 2.1 \\
91.3-99.6\end{array}$ & $\begin{array}{l}96.1 \pm 2.7 \\
90-99\end{array}$ & $\begin{array}{l}96 \pm 1.9 \\
(92-98)\end{array}$ & $\begin{array}{l}96.3 \pm 2 \\
(93-99)\end{array}$ & $\begin{array}{l}94.8 \pm 2.5 \\
(90-97)\end{array}$ \\
\hline $\mathrm{PaO}_{2} / \mathrm{FiO}_{2}$ & $\begin{array}{l}190.5 \pm 61.5 \\
96-335\end{array}$ & $\begin{array}{l}189.2 \pm 64 \\
82-315\end{array}$ & $\begin{array}{l}171.4 \pm 48.8 \\
(121-311)\end{array}$ & $\begin{array}{l}171.3 \pm 51.8 \\
(67-254)\end{array}$ & $\begin{array}{l}180.3 \pm 46.1 \\
(125-270)\end{array}$ \\
\hline HFNO Flow (L minute ${ }^{-1}$ ) & $\begin{array}{l}51.3 \pm 4.9 \\
40-60\end{array}$ & $\begin{array}{l}46.7 \pm 8.3 \\
20-60\end{array}$ & $\begin{array}{l}45.9 \pm 4.1 \\
(40-50)\end{array}$ & $\begin{array}{l}43.6 \pm 5 \\
(35-50)\end{array}$ & $\begin{array}{l}42.2 \pm 8.7 \\
(30-60)\end{array}$ \\
\hline $\mathrm{FiO}_{2}$ & $\begin{array}{l}0.5 \pm 0.1 \\
0.4-1\end{array}$ & $\begin{array}{l}0.4 \pm 0.1 \\
(0.3-0.8)\end{array}$ & $\begin{array}{l}0.4 \pm 0.1 \\
(0.3-0.7)\end{array}$ & $\begin{array}{l}0.49 \pm 0.08 \\
(0.3-0.6)\end{array}$ & $\begin{array}{l}0.46 \pm 0.07 \\
(0.3-0.6)\end{array}$ \\
\hline
\end{tabular}


Table 4

Correlation between clinical features and pre-extubation respiratory parameters

\begin{tabular}{|c|c|c|c|c|}
\hline & \multicolumn{2}{|c|}{$\begin{array}{l}\text { HFNO duration after } \\
\text { extubation (days) }\end{array}$} & \multicolumn{2}{|c|}{$\begin{array}{l}\text { ICU hospitalization } \\
\text { (days) }\end{array}$} \\
\hline & $r$ & $\mathrm{p}$ & $r$ & $\mathrm{p}$ \\
\hline Age (years) & -0.214 & 0.339 & 0.006 & 0.980 \\
\hline $\mathrm{BMI}\left(\mathrm{kg} \mathrm{m}^{-2}\right)$ & -0.199 & 0.381 & -0.140 & 0.536 \\
\hline $\begin{array}{l}\text { Duration between semptom initiation and ICU } \\
\text { admission (days) }\end{array}$ & -0.149 & 0.509 & 0.384 & 0.077 \\
\hline $\begin{array}{l}\text { Duration between semptom initiation and } \\
\text { intubation (days) }\end{array}$ & -0.158 & 0.483 & 0.374 & 0.086 \\
\hline APACHE II score at ICU admission & 0.117 & 0.603 & 0.381 & 0.080 \\
\hline SOFA score at ICU admission & 0.384 & 0.078 & 0.186 & 0.408 \\
\hline Maximum SOFA score & 0.352 & 0.109 & 0.346 & 0.114 \\
\hline $\mathrm{PaO}_{2} / \mathrm{FiO}_{2}$ before intubation & 0.312 & 0.157 & 0.169 & 0.452 \\
\hline Duration of mechanic ventilation (days) & -0.334 & 0.129 & 0.476 & $0.025^{\star}$ \\
\hline $\mathrm{pH}$ before extubation & 0.438 & $0.041^{*}$ & 0.119 & 0.597 \\
\hline $\mathrm{PO}_{2}$ before extubation $(\mathrm{mmHg})$ & -0.254 & 0.253 & -0.054 & 0.813 \\
\hline $\mathrm{PCO}_{2}$ before extubation $(\mathrm{mmHg})$ & -0.055 & 0.808 & 0.007 & 0.975 \\
\hline $\mathrm{HCO}_{3}$ before extubation $\left(\mathrm{mmol} \mathrm{L}^{-1}\right)$ & 0.109 & 0.628 & 0.138 & 0.541 \\
\hline Bas excess before extubation & 0.137 & 0.542 & 0.117 & 0.605 \\
\hline $\mathrm{SaO}_{2}$ before extubation (\%) & -0.140 & 0.533 & 0.037 & 0.871 \\
\hline Respiratory rate before extubation & -0.069 & 0.762 & 0.196 & 0.382 \\
\hline Tidal Volume before extubation (ml) & -0.017 & 0.941 & -0.186 & 0.408 \\
\hline RR/Vt before extubation & -0.076 & 0.736 & 0.198 & 0.378 \\
\hline PEEP before extubation & 0.094 & 0.678 & -0.481 & $0.023^{*}$ \\
\hline Inspiration support before extubation & -0.409 & 0.059 & 0.284 & 0.200 \\
\hline
\end{tabular}

BMI: body mass index, ICU: intensive care unit, APACHE II: acute physiology and chronic health evaluation II, SOFA: sequential organ failure assessment, HFNO: high flow nasal oxygen, $\mathrm{PaO}_{2}$ : arterial oxygen partial pressure, $\mathrm{FiO}_{2}$ : fractional inspired oxygen, RR: respiratory rate, Vt: tidal volume, $\mathrm{SaO}_{2}$ : arterial oxygen saturation, PEEP: positive end expiratory pressure, *: Statistically significant 
HFNO duration after

extubation (days)
ICU hospitalization (days)
$\mathrm{FiO}_{2}$ before extubation
0.044
0.846
$-0.434$
$0.043^{*}$
$\mathrm{PaO}_{2} / \mathrm{FiO}_{2}$ before extubation
$-0.211$
0.345
0.188
0.401

BMI: body mass index, ICU: intensive care unit, APACHE II: acute physiology and chronic health evaluation II, SOFA: sequential organ failure assessment, HFNO: high flow nasal oxygen, $\mathrm{PaO}_{2}$ : arterial oxygen partial pressure, $\mathrm{FiO}_{2}$ : fractional inspired oxygen, $\mathrm{RR}$ : respiratory rate, $\mathrm{Vt}$ : tidal volume, $\mathrm{SaO}_{2}$ : arterial oxygen saturation, PEEP: positive end expiratory pressure, *: Statistically significant

\section{Discussion}

The main finding of the present retrospective data is that high-risk ARDS COVID-19 patients can be successfully extubated to HFNO. Among the non-invasive modalities, high flow oxygen therapy offers many physiological benefits which include improved oxygenation, decreased anatomical dead space, decreased metabolic demand of breathing, decreased production of carbon dioxide. Most importantly this technique serves up to superior comfort and improved work of breathing. In a small group of patients, the delivery of heated and humidified oxygen with high-flow nasal cannula was shown to be superior to high-flow oxygen via a non-rebreathing mask. Breathing frequency and inspiratory effort were reduced with HFNO compared with the non-rebreathing mask. HFNO therapy decreases post-extubation neuroventilatory drive and work of breathing in patients with chronic obstructive pulmonary disease [5]. We did not measure electrical diaphragmatic activity, but we think that HFNO treatment reduces the possibility of reintubation due to high ventilatory impulse and respiratory work in patients with extubated COVID-19 ARDS.

Many other studies showed that HFNO was superior to COT in reducing treatment failure when used as a primary support strategy and in reducing rates of extubation failure [6]. In a few trials, HFNO reduced the intubation rate compared to NIV when used as initial support but demonstrated no beneficial effects after extubation. Post extubation respiratory failure and reintubation rates were compared between HFNO and non-invasive ventilation in a group of high-risk patients. In this multicentric randomized clinical trial, HFNO offered many clinical advantages and proved that it is not inferior to NIV for preventing reintubation and post-extubation respiratory failure. A higher reintubation rate was reported (19\%) with NIV most probably due to switching to COT after 24 hours $[7,8]$. Other data suggest that more prolonged high-flow conditioned oxygen therapy could improve outcomes in critically ill patients after extubation [9]. In a general population of critically ill patients randomized to receive either high-flow conditioned oxygen therapy or COT for 48 hours, Maggiore and colleagues found persistent improvement in oxygenation and comfort parameters and achieved a lower reintubation rate (3.8\%) [10]. In another multicentric randomized trial including high-risk extubation failure patients, the reintubation rate was $18.2 \%$ with 48 hours HFNO treatment [11]. The reintubation rate was $10 \%(2 / 20)$ in our retrospective data which was similar to previous trials. We continued HFNO treatment for 48 hours after planned extubation after which 
they switch to standard oxygen therapy. Considering the high risk of COVID-19 ARDS patients for extubation, prolonging the HFNO therapy for at least 5 days could improve extubation success.

Several reports discussed if endotracheal intubation could be prevented by HFNO treatment in COVID-19 patients who presented with acute respiratory failure with moderate ARDS. Twelve randomized controlled trials provided low-certainty evidence that HFNO may reduce invasive ventilation in non-COVID-19 patients [2]. Results provided no support for differences in mortality or length of ICU stay. HFNO seems to have been seldomly used during the current COVID-19 pandemic in the western world. This is most probably due to the fear of risk of aerosolization and viral dispersion which might lead to infection transmission. However, the World Health Organization and other scientific societies list HFNO among the possible options for ventilator support [12]. Four studies evaluating droplet dispersion and three evaluating aerosol generations and dispersion provided very low certainty evidence. Two simulation studies and a crossover study showed mixed findings regarding the effect of HFNO on droplet dispersion. Although two simulation studies reported no associated increase in aerosol dispersion, one reported that higher flow rates were associated with increased regions of aerosol density [13-21]. However, in-vitro and clinical studies demonstrated that placing a simple surgical protection mask on patients significantly reduces dispersion distance [22]. Smoke simulation studies also demonstrated that dispersion with a flow rate of $60 \mathrm{~L}$ minute ${ }^{-1}$ is similar to the one observed with a simple oxygen mask at $15 \mathrm{~L}$ minute ${ }^{-1}[13$, 23]. We followed the same rule that all patients wore a facial mask during HFNO treatment and the mean flow rates were lower than $50 \mathrm{~L}_{\text {minute }}{ }^{-1}$ in 5 days' follow-up after extubation which we believed that sustained minimum dispersion.

Our data evaluation has several limitations first being its retrospective nature. Second, we did not have a control group so that we were not able to compare the data with other respiratory support systems. We haven't used any fixed protocol in terms of time period after extubation. However, patients were switched to a standard oxygen mask when they fulfill the necessary clinical and respiratory criteria. Third, the number of patients might not be enough to come to any strong conclusion however we think that the rate of extubation success in our data of high risk of COVID-19 patients worth considering.

\section{Conclusions}

Among high-risk ARDS COVID-19 patients who have undergone extubation, HFNO therapy should be considered for preventing reintubation and post-extubation respiratory failure.

\section{Abbreviations}

COVID-19: Coronavirus disease- 2019

ARDS: Acute respiratory distress syndrome

HFNO:High Flow Nasal Cannula Oxygen Therapy

Page 13/16 
ICU:Intensive care unit

NIV:Non-invasive ventilation

COT:Conventional oxygen treatment

RT-PCR:Reverse-transcriptase-polymerase-chain-reaction

APACHE II: Acute Physiology and Chronic Health Evaluation II

SOFA: Sequential Organ Failure Assessment

PEEP: Positive end-expiratory pressure

Vt:Tidal volume

$\mathrm{SaO}_{2}$ :Arterial oxygen saturation

HR: Heart rate

\section{Declarations}

\section{Ethics approval and consent to participate}

The ethics approval was obtained from the hospital's local ethics committee (Approval number: 04/06/2020-89807).

\section{Consent for publication}

Not applicable.

\section{Availability of data and materials}

Not applicable.

\section{Competing interests}

The authors declare that they have no conflict of interests.

\section{Funding}

None

\section{Authors' contributions}

Conception and design: GHA, FE, and PEO, Data collection: GHA, OP, IA, GO, VT, EC, MK, and MT, Interpretation of data: GHO, FE, and OP, Data analysis: GHA, Writing the manuscript: GHA, Supervision: FE 
and PEO, Critical revision: FE, PEO.

\section{Acknowledgements}

None

\section{References}

1. Dysart K, Miller TL, Wolfson MR, Shaffer TH. Research in high flow therapy: mechanisms of action. Respir Med. 2009;103:1400-5.

2. Agarwal A, Basmaji J, Muttalib F, et al. High-flow nasal cannula for acute hypoxemic respiratory failure in patients with COVID-19: systematic reviews of effectiveness and its risks of aerosolization, dispersion, and infection transmission. Can J Anaesth. 2020;15:1-32.

3. Li J, Fink JB, Ehrmann S. High-flow nasal cannula for COVID-19 patients: low risk of bio-aerosol dispersion. Eur Respir J. 2020;55:2000892.

4. ARDS Definition Task Force. Ranieri VM, Rubenfeld GD, Thompson BT, Ferguson ND, Caldwell E, Fan E, Camporota L, Slutsky AS. Acute Respiratory Distress Syndrome: The Berlin Definition. JAMA 2012;307(23):2526-33.

5. Di Mussi R, Spadaro S, Stripoli T, et al. High-flow nasal cannula oxygen therapy decreases postextubation neuroventilatory drive and work of breathing in patients with chronic obstructive pulmonary disease. Crit Care. 2018;22(1):180.

6. Xu Z, Li Y, Zhou J, et al. High-flow nasal cannula in adults with acute respiratory failure and after extubation: a systematic review and meta-analysis. Respir Res. 2018;19(1):202.

7. Nava S, Gregoretti C, Fanfulla F, et al. Noninvasive ventilation to prevent respiratory failure after extubation in high-risk patients. Crit Care Med. 2005;33(11):2465-70.

8. Hernández G, Vaquero C, Colinas L, et al. Effect of Postextubation High-Flow Nasal Cannula vs Noninvasive Ventilation on Reintubation and Postextubation Respiratory Failure in High-Risk Patients A Randomized Clinical Trial. JAMA. 2016;316(15):1565-74.

9. Hernández G, Roca O, Colinas L. High-flow nasal cannula support therapy: new insights and improving performance. Crit Care. 2017;21(1):62.

10. Maggiore SM, Idone FA, Vaschetto R, et al. Nasal high-flow versus Venturi mask oxygen therapy after extubation. Effects on oxygenation, comfort, and clinical outcome. Am J Respir Crit Care Med. 2014;190(3):282-8.

11. Thille AW, Muller G, Gacouin A, et al. Effect of Postextubation High-Flow Nasal Oxygen With Noninvasive Ventilation vs High-Flow Nasal Oxygen Alone on Reintubation Among Patients at High Risk of Extubation Failure A Randomized Clinical Tri. JAMA. 2019;322(15):1465-75.

12. World Health Organization. Rolling updates on coronavirus disease (COVID-19). Available from URL: https://www.who.int/emergencies/diseases/novel-coronavirus-2019/events-as-they-happen (accessed May 2020). 
13. Hui DS, Chow BK, Lo T, et al. Exhaled air dispersion during high-flow nasal cannula therapy versus CPAP via different masks. Eur Respir J 2019; 53.

14. Loh WN, Tan Y, Taculod J, et al. The impact of high-flow nasal cannula (HFNC) on coughing distance: implications on its use during the novel coronavirus disease outbreak. Can J Anesth. 2020. DOl:https://doi.org/10.1007/s12630-020-01634-3.

15. Kotoda M, Hishiyama S, Mitsui K, et al. Assessment of the potential for pathogen dispersal during high-flow nasal therapy. J Hosp Infect. 2020. DOI:https://doi.org/10.1016/j.jhin.2019.11.010.

16. Leung $\mathrm{CCH}$, Joynt GM, Gomersall CD, et al. Comparison of high-flow nasal cannula versus oxygen face mask for environmental bacterial contamination in critically ill pneumonia patients: a randomized controlled crossover trial. J Hosp Infect. 2019;101:84-7.

17. Leonard S, Atwood CW Jr, Walsh BK, et al. Preliminary findings on control of dispersion of aerosols and droplets during high velocity nasal insufflation therapy using a simple surgical mask: implications for the high-flow nasal cannula. Chest. 2020.

DOl:https://doi.org/10.1016/j.chest.2020.03.043.

18. Iwashyna TJ, Boehman A, Capelcelatro J, et al. Variation in aerosol production across oxygen delivery devices in spontaneously breathing human subjects. medRxiv - 2020. Available from URL: https://www.medrxiv.org/content/10.1101/ 2020.04.15.20066688v1 (accessed May 2020).

19. Roberts S, Kabaliuk N, Spence C, et al. Nasal high flow therapy and dispersion of nasal aerosols in an experimental setting. J Crit Care. 2015;30:842. (abstract).

20. Van Doremalen N, Bushmaker T, Morris DH, et al. Aerosol and surface stability of SARS-CoV-2 as compared with SARS-CoV- 1. N Engl J Med. 2020. DOl:https://doi.org/10.1056/NEJMc2004973.

21. Bischoff WE, Swett K, Leng I, Peters TR. Exposure to influenza virus aerosols during routine patient care. J Infect Dis. 2013;207:1037-46.

22. Hui DS, Chow BK, Chu L, et al. Exhaled air dispersion during coughing with and without wearing a surgical or N95 mask. PLoS One. 2012;7:e50845.

23. Ip M, Tang JW, Hui DS, et al. Airflow and droplet spreading around oxygen masks: a simulation model for infection control research. Am J Infect Control. 2007;35:684-9.

\section{Supplementary Files}

Supplement 1 is not available with this version 